\title{
SME Characteristics and Value Added Tax Compliance Costs In Nigeria
}

\author{
Eragbhe E. (Ph.D) \\ Dept. of Accounting, University of Benin \\ Eragb1@gmail.com \\ Omoye, A.S (Ph.D) \\ Dept. of Accounting, University of Benin \\ alade.omoye@uniben.edu
}

\section{Doi:10.5901/mjss.2014.v5n20p614}

\begin{abstract}
This study examines the effect of SME characteristics on tax compliance cost in Nigeria. Specifically, it investigates the effect of Business age (LIFET), Outsourcing (OUTS), Employee size (WRKS), Export status (FOT), Turnover (TURO), Industry class (INDCLAS) and Distance to tax office (DISTANCE) on tax compliance costs for Value Added Tax (VAT) in Nigeria. The study utilized the survey research design using questionnaire as the research instrument and primary data as the data type. The population consists of all registered SME's in Nigeria as at the study period. A sample of 750 taxpaying SMEs across the six (6) geo-political zones of Nigeria was used for the study and this was done using the purposive sampling technique. 597 responses were received out of which 574 were adjudged valid. Our analysis revealed that the effect of LIFT, TURO, INDCLAS, DISTANCE and WRKS on Tax Compliance Costs of VAT (CVAT) is negative while the effect of FOT and OUTSOURCING appear to be positive. However, none of the variables appear to be significant going by their t-ratios and this suggests that SME attributes do not impact significantly on CVAT in Nigeria. The study concludes that the porosity of the tax system coupled with the fact that the activities of SME's in developing countries are domiciled within the shadow economy may explain the insignificance of SME attributes in determining and hence in predicting tax compliance costs. This study on this note, suggests that more empirical studies are needed in Nigeria in this areas.
\end{abstract}

Keywords: Tax compliance cost, Small and Medium scale enterprises, Taxation and Business age

\section{Introduction}

The replacing of sales tax with the value-added tax (VAT) through the VAT Act No. 102 of 1993 was an important landmark in tax reform in Nigeria. Since its introduction, 15 of the 47 sections of the Act have been amended, the latest being the Value Added Tax (amendment) Act of 2007. VAT was originally imposed on 17 categories of goods and 24 service categories. In Nigeria, although VAT is a consumption tax, a 5 per cent rate is levied on suppliers (i.e. taxable individuals) who are expected to add this amount to invoices for collection from customers and for further remittance to the VAT authorities on a monthly basis. VAT is retained at 5 per cent regardless of the stage of production or distribution. This assumes the absence of cascading effects. It is a non-discriminatory tax with regard to locally manufactured or imported goods. The Act designated the Federal Inland Revenue Service (FIRS) as the responsible instance for implementing VAT. Globally, the introduction of VAT in most countries has significantly increased business tax compliance costs. They represent an additional burden on taxpayers, including SME taxpayers which are acting as unpaid tax collectors, especially in the case of VAT compliance costs (Pope, 2001).These compliance costs compass mainly record keeping for VAT-purposes only, preparation and filling of VAT returns, checking accounts, obtaining information about new procedures for filling VAT returns, changes in the law and other relevant information (O'Keefe and O'Hare, 2008). Research reveals that relative compliance costs according to VAT are a relatively higher burden for small business (Pope and Rametse, 2001). Specifically, Massey (2003) found using SME's in New Zealand that the mean VAT compliance costs for the smallest companies represented $2.7 \%$ of their turnover as compared to only $0.005 \%$ for the largest companies. Importantly also, VAT was cited as the largest source of tax compliance costs in 8 out of 11 OECD countries that were surveyed (Pope, 2001).

The need to investigate VAT Compliance cost and indeed the compliance cost of other tax derivatives for developing countries like Nigeria is borne out of the role of tax compliance costs in influencing foreign investments. In this regards, the World Bank group and Price Waterhouse Coopers (2008), have shown that tax levels and the accompanying 
administration are the greatest barriers for a company to settle in a particular country. The public interest in reducing the tax compliance costs especially for SMEs has resulted in publications in the U.S., Australia, UK, Singapore, Hong Kong, Croatia, South Africa, Canada, Malaysia, The Netherlands, India and New Zealand and Belgium (Evans, 2003, PWC, 2008; PWC, 2009; PWC, 2010) but no specific interest has been given to this issue in Nigeria. According to Blazic (2004) tax compliance costs research is still very rare among transition countries either because it requires investigation which involves the collection of large amounts of data not available from published sources, or because there has been a general apathy towards the problem. The broad objective of the study is to examine the role of SME characteristics in influencing Value Added Tax compliance costs in Nigeria.

\section{Literature Review and Hypotheses Development}

\subsection{Concept of Tax Compliance Cost}

Different definitions of the term 'tax compliance costs' exist, an agreement as to the exact meaning of tax compliance cost only began to emerge in the literature about 3 decades ago when researches on TCC left its hitherto state of obscurity to a familiar terrain. Evans (2003) observed that there is now an extensive and varied literature available that deals with issues relating to tax compliance costs. Sapiei and Kasipillai (2009) argue that the challenges faced in tax compliance cost research particularly in its definition and measurement remains an important issue. The absence of well-built consensus to the extra connotation of tax compliance cost remains a puzzle. However, a preponderance of definitions still abounds in the tax compliance costs literature. Sandford (1995) defines the concept of tax compliance costs, as follows:

TCC are the costs incurred by taxpayers in meeting the requirements laid on them by the tax law and the revenue authorities. These are costs over and above the actual payment of tax and over and above any distortion costs inherent in the nature of the tax. These costs would disappear if the tax was abolished. They include the costs of collecting, remitting and accounting for tax on the products and profits of the business and on the wages and salaries of its employees, and also the costs of acquiring and updating the knowledge to enable this work to be done, including knowledge or legal obligations and penalties. (Sandford, 1995, p 1)

Americans for Fair Taxation (2007) sees tax compliance costs as the total time and money spent on filling out tax forms, keeping records, learning tax rules, and other tax-related matters. Compliance costs of taxation are amount of resources expended by taxpayers, in addition to the amount of tax they are required to pay, in conforming to the requirements of the relevant tax legislation. Compliance costs are not only incurred by taxpayers but by all the agents/parties involved in making possible the transfer of funds from the private sector to the government department that controls public money.

In this study we define compliance costs as all costs, besides the actual tax liability, born by taxpayers and third parties in the process of ensuring that they comply with the provisions of the relevant tax laws and the requirements laid on them by the relevant taxing authorities, including the inconveniences encountered in the process of becoming and remaining tax compliant.

\subsection{SME Characteristics and Tax Compliance Cost}

In this section, we examine the theoretical link between the characteristics of SMEs and tax compliance Costs. Consequently, we shall state the hypothesized relationships.

\subsubsection{Business Age and Tax Compliance Costs}

There is the assertion that younger businesses bear higher tax compliance costs when compared with older businesses. This is largely occasioned by high start-up costs and learning curve effects. Tran-Nam and Glover (2002); Rametse and Pope (2002); Hansford, Helseldine and Howorth (2003) and Eichfelder and Schorn (2008) studied start-up cost of tax compliance. While Tran-Nam and Glover (2002) and Rametse and Pope (2002) found empirical relationships between tax compliance costs and start-up costs, Hansford et al. (2003) and Eichfelder and Schorn (2008) found no empirical evidence between business age and tax compliance costs

H1: Business age is not a significant determinant of VAT compliance costs in Nigeria. 


\subsubsection{Business Size and Tax Compliance Cost}

There is a general belief that a relationship exist between the size of a business and its level of tax compliance costs. It might be true that smaller businesses have relatively higher tax compliance costs when compared with big businesses. Hence bigger SMEs seem to benefit from economies of scale. Several studies conclude that the relation between company size and the ratio of compliance costs/turnover is negatively correlated. It can be inferred that the bigger the business, the lower the compliance costs (Pope, 2001; Hanefah et al., 2002; Pope, 2002; Slemrod and Venkatesh, 2002; Lignier, 2006; Charron et al., 2008).

H1: Business size is not a significant determinant of VAT compliance costs in Nigeria.

\subsubsection{Industry Type and Tax Compliance Cost}

In a number of countries, studies have been undertaken to examine the impact of industries on business tax compliance costs (Blumenthal and Slemrod, 1996; Chan et al, 1999; Slemrod and Venkatesh, 2002). In general, tax compliance costs researches show that there exists a wide variation in tax compliance costs by industry type. From all these studies there were no univocal conclusions that regarding the effect of industry on tax compliance cost. In Hong Kong differences were found, but only by using the absolute compliance costs. No significant differences could be discovered when using the compliance costs relatively to sales (Chan et al., 1999). The only existing research that showed significant differences between industries is that conducted by Blumenthal and Slemrod (1996). They find that firms in the retail or wholesale industry have significantly lower tax compliance costs and that firms in the primary industry have significantly higher than average tax compliance costs.

H2: Industry Type is not a significant determinant of VAT compliance costs in Nigeria.

\subsubsection{Workforce and Tax Compliance Cost}

Employee taxes collected by SMEs generate the most part of the compliance cost of the companies if it has a large workforce. In other words, SMEs are not only financing the government, they are also subcontractors for the collection of taxes. PWC (2007) stated that companies with large workforce are the largest tax collection agent and that they will probably have also the highest tax compliance costs.

H3: Workforce is not a significant determinant of VAT compliance costs in Nigeria.

\subsubsection{Outsourcing and Tax Compliance Cost}

A major feature of SMEs with taxpaying history is their use of tax professionals. These tax professionals can be classified as internal and external tax professionals. The cost incurred for paying internal tax personnel is described as internal cost while the fee charged by outside tax consultants is known as external cost. Internal costs have in general a larger attribution in the total compliance costs, especially in large SMEs. Research has indicated that most activities that are necessary to comply with the fiscal legislation are performed by internal departments. Additionally, external consultants are hired to a limited extent for advice or document completion (Blumenthal and Slemrod, 1996). More complex tasks are often outsourced to external accountants. Coolidge, llic, and Kisunko, (2009) showed that SMEs that outsourcing has a positive effect on tax compliance cost.

H4: Outsourcing is not a significant determinant of VAT compliance costs in Nigeria.

\subsubsection{Distance and Tax Compliance Cost}

In Nigeria, SMEs are located in different parts of the country, rural and urban. Tax offices, on the other hand, do not enjoy the luxury of such location which implies that tax paying SMEs are required to move from their place of business to the relevant tax offices closest to them to fulfill their tax obligations. This results in transportation costs which forms part of the compliance costs. Distance from tax office may also affect the psych of the taxpayer and create huge inconveniences which are also part of the tax compliance costs. We are of the opinion that the farther the distance of the SMEs place of business from the tax office the higher the transportation costs and hence the higher would be the compliance costs. This variable, (distance from tax office) has, to our knowledge, never been studied and hence no empirical evidence exist in the literature. We are about the first to attempt to include this variable in the study of tax compliance costs. 
H5: Distance is not a significant determinant of VAT compliance costs in Nigeria.

\section{Methodology}

The research design for this study is the survey research design. The population for this study is all SMEs in Nigeria with a history of paying taxes. A recent study undertaken by the Small and Medium Enterprises Development Agency of Nigeria (SMEDAN) and the National Bureau of Statistics (NBS) put micro, small and medium businesses across the country in the region of 17.3 million. For our sample, we adopted the Yamane (1967) sample size calculation based on the number of SMEs in Nigeria. This produced a sample size of 400 as a minimum for this study. However a reasonably large sample of 750 taxpaying SMEs across the country was adopted. This became necessary in order to ensure adequate representation and reliable generalization. To avoid regional bias, we ensured that at least a minimum of 50 SMEs that pay taxes from each of the six geopolitical zones in Nigeria is included in the sample. The study therefore adopts a cluster and purposive sampling technique and the justification is based on the need to avoid selection and representativeness bias. The research instrument used for the study is divided into several sections. The first section (Section $\mathrm{A}$ ) of the questionnaire gathered data relating to the characteristics of the SME's. The second section (Section B) collected data on internal tax compliance costs of VAT and other types of taxes in Nigeria. Respondents were asked to give their best estimate on how much time they spend on each tax and the cost they have to make to comply with these taxes. The third section (Section C) of the questionnaire collected data on external compliance costs for VAT and other taxes in Nigeria. Specifically, respondents were asked if they seek the assistance of tax professionals in understanding and complying with the type of taxes they pay. For the purpose of analysis, respondents were asked to give their best estimate of the average fees per year spent on professional charges on these taxes. The fourth section (Section D) collected data on bribery and psychological costs associated with tax compliance for VAT and other taxes in Nigeria. Respondents were asked if they experience stress, anxiety or frustration when complying with the various taxes. Specifically, in estimating psychological TCC, we requested information on what the business may be willing to pay to avoid the stress and anxiety that arise from complying with a specific tax or from a tax-related activity, and to avoid the frustration resulting from harassment from tax officials. This approach for measuring psychic cost of tax compliance is similar to the approach adopted in a survey of large corporations in India by Bhatnagar, Chattopadhyay, Das-Gupta, Mohanty, Mukhopadhyay and Singh (2002).

Consequently, the measurement of the total tax compliance costs (TAXCP) and the total VAT compliance cost (CVAT) is presented below;

TAXCP = The Aggregate tax compliance costs (VAT compliance costs +Employee tax compliance costs + Withholding tax compliance costs + business/company income tax compliance costs +educational tax compliance costs + custom and excise duties tax compliance costs). These costs include internal staff costs, external tax fees, incidental costs such as bribery costs and psychological costs.

CVAT = The sum of Internal compliance costs, external compliance costs, bribery and psychological costs related to value added tax.

\subsection{Model Specification}

The model examines the effect of SME characteristics on VAT compliance costs. The model is presented below;

$$
\frac{C V A T}{T A X C P}=\alpha_{1}+\beta_{8} T U R O+\beta_{9} L I F E T+\beta_{10} F O T+\beta_{11} I N D C L A S+\beta_{12} O U T S+\beta_{13} W R K S+\beta_{14} D I S T+\varepsilon_{t}
$$

Where;

$\frac{C V A T}{\text { TAXCP }}=$ SMEs compliance costs of VAT as a ratio of total tax compliance costs.

TURO = The size of SMEs measured by gross turnover. In the survey we classified SMEs into one of three different classes: (1) Less than N500,000 for Micro-sized Enterprises (2) N500,000 to N5million for Small-Sized Enterprise and (3) More than N5million for Medium-Scale Enterprises.

LIFET = The number of years in business. Respondents were asked to classify their company into one of four different classes: 0 to 2 years, 3 to 5 years, 6 to 14 years and 15 years and above.

FOT $=$ Foreign operations i.e. exporting activities. SMEs were divided according to their international business activities. Participating SMEs were asked to indicate whether they engage in exporting activities and the continent where they export to. The question outcomes are: No export, Export within Africa and Export across the globe.

INDCLAS = Industry classification. A categorical variable was used to measure SMEs classification into different 
industries. This variable has ten different categories. The following breakdown as derived from Inegbenebor (2006) was used; (1) Agriculture, hunting, forestry, mining and quarrying, livestock and fishing; (2) Manufacturing; (3) Building and Construction; (4) Wholesale and retail trade. (5) Hotels and restaurants; (6) Transport; (7) Real estate and housing; (8) Communications; (9) Utilities; (10) Finance, Insurance and Business Services. In our regression analysis, the industries were re-grouped into services and non-services industry.

OUTS = SMES outsourcing activities. We adopted dummy in this case. The companies handling all the activities relating to tax solely with internal staff was assigned a value of "1", the companies that partially outsource these tasks was assigned a value of "2" while the companies that completely outsource these tasks was assigned a value of "3"

WRKS = The number of SMEs full time employees. This question was added in order to determine whether or not the employee size has an influence on the level of compliance costs.

DIST = The distance of SMEs to the nearest tax office. The SMEs that are very far from tax office were assigned a value of "3", the SMEs that are relatively close to tax office were assigned a value of "2" while the SMEs that are very close to tax office were assigned a value of "1".

\section{Presentation and Analysis of Result}

Table 1. SMEs VAT Tax compliance cost regression results

\begin{tabular}{|c|c|c|}
\hline Variables & Disaggregated CVAT & Apriori Sign \\
\hline & Model 2 & \\
\hline & CVAT & \\
\hline \multirow[t]{3}{*}{$\mathrm{C}$} & 77064.8 & \\
\hline & $\left(3.62^{\prime}\right)$ & \\
\hline & {$[0.000]$} & \\
\hline \multirow[t]{3}{*}{ LIFET } & -4276.6 & $+1-$ \\
\hline & $(-1.06)$ & \\
\hline & {$[0.290]$} & \\
\hline \multirow[t]{3}{*}{ OUTS } & 2343.7 & + \\
\hline & $\left(0.5^{\prime}\right)$ & \\
\hline & {$[0.616]$} & \\
\hline \multirow[t]{3}{*}{ WRKS } & -2851.7 & + \\
\hline & $\left(-0.75^{\prime}\right)$ & \\
\hline & [0.455] & \\
\hline \multirow[t]{3}{*}{ FOT } & 1883.9 & + \\
\hline & $\left(0.17^{\prime}\right)$ & \\
\hline & {$[0.864]$} & \\
\hline \multirow[t]{3}{*}{ TURO } & -2067.5 & $-1+$ \\
\hline & $(-0.77)$ & \\
\hline & [0.441] & \\
\hline \multirow[t]{3}{*}{ INDCLAS } & -3573.9 & $-1+$ \\
\hline & $(-0.41)$ & \\
\hline & [0.684] & \\
\hline \multirow[t]{3}{*}{ DISTANCE } & -591.9 & + \\
\hline & $(-0.19)$ & \\
\hline & {$[0.848]$} & \\
\hline R-squared & 0.281 & \\
\hline Prob(F-Stat) & 0.0903 & \\
\hline $\mathrm{N}$ & 249 & \\
\hline
\end{tabular}

Source: Researchers Computation (2014)

Table 1, shows how SMEs characteristics such as Business age (LIFET), Outsourcing (OUTS), Employee size (WRKS), Export status (FOT), Turnover (TURO), Industry class (INDCLAS) and Distance to tax office (DISTANCE) determine average tax compliance cost of VAT (CVAT) in Nigeria. The value of the R-squared from the regression model shows that over 28\% of the systematic variations in CVAT is jointly explained by SMEs characteristics. The F-statistic $p$-value of 0.0903 implies that the model is significant at $5 \%$ level. This indicates that there exists a significant linear relationship 
between the dependent and independent variables. The performance of the slope coefficients indicates that the effect of LIFT, TURO, INDCLAS, DISTANCE and WRKS on CVAT is negative while the effect of FOT and OUTSOURCING appear to be positive. However, none of the variables appear to be significant going by their t-ratios and hence we fail to reject the hypothesis $(\mathrm{H} 1-\mathrm{H} 6)$ and this suggest that SME attributes do not impact significantly on tax compliance costs of VAT in Nigeria. These findings follow in the line of studies (Blumenthal and Slemrod, 1996; Chan et al, 1999; Slemrod and Venkatesh, 2002), where empirical evidence has been found to be largely inconclusive. The porosity of the tax system coupled with the fact that the activities of SME's in developing countries are domiciled within the shadow economy may explain the insignificance of SME attributes in determining and hence in predicting tax compliance cost.

\section{Conclusion}

The aim of this paper is to provide greater insight into how SME characteristics may influence tax compliance costs of VAT in developing economies. Following the variedness in SME attributes, we argue that Business age (LIFET), Outsourcing (OUTS), Employee size (WRKS), Export status (FOT), Turnover (TURO), Industry class (INDCLAS) and Distance to tax office (DISTANCE) determine average VAT compliance costs in Nigeria. To assess our arguments, we estimate the required relationship using regression analysis. We find clearly that none of the variables appear to be significant going by their t-ratios and this suggests that SME attributes do not impact significantly on CVAT in Nigeria. We therefore conclude that understanding SMEs tax compliance costs for VAT requires explanations that are outside the characteristics of SMEs. Policy makers in Nigeria may need to focus on external factors such as economic, social, technology, political and infrastructural facilities as likely factors that might influence SMEs VAT compliance costs. This study on this note, suggests that more empirical studies are needed in Nigeria in this areas.

\section{References}

Americans for Fair Taxation (2007). What the federal tax system is costing you - besides your taxes! Tax compliance facts. www.FairTax.org

Ariff, M., Loh, A.L.C., \& Ismail, Z. (1997). Compliance cost of corporate income taxation in Singapore. Journal of Business, Finance and Accounting, 29, 1253-1268.

Bhatnagar, D., Chattopadhyay, S., Das-Gupta, A., Mohanty, J., Mukhopadhyay, S., \& Singh, S. (2002). The income tax compliance cost of Indian corporations. National institute of public finance and policy New Delhi

Blazic, H. (2004). Tax compliance costs of Small Business in Croatia. Retrieved from http://www.iweb.cerge-ei.cz/pdf/gdn IRRCII_11_paper_05.pdf

Blumenthal, M., \& Slemrod, J. B. (1996). The income tax compliance costs of big businesses. Public finance quarterly, 24 (4) , 411-38 .

Blumenthal, M. and Slemrod, J.B., (1992). The compliance cost of the U.S. individual income tax sytem: A second look after tax reform. National Tax Journal, 45(2), 185-202.

Chan, S., Cheung, D., Ariff, M., \& Loh. A. (1999). Compliance costs of corporate taxation in Hong Kong. International Tax Journal, 25(4), 42-68.

Cnossen, S. (1994). Administrative and compliance costs of the vat: a review of the evidence. Tax notes international 1649.

Coolidge, J., llic,D., \& Kisunko, G. (2009). Small businesses in South Africa: who outsource tax compliance work and why?, Policy research working paper 4873, world bank.

Evans, C., Ritchie, K., Tran-Nam, B., \& Walpole, M. (1997). Taxpayer costs of compliance. Sydney; ATAX : UNSW.

Evans, C. (2001). The operating costs of taxation: a review of the research. Journal of the Institute of Economic Affairs, 21(2), 5-10.

Evans, C. (2003). Studying the studies: An overview of recent research into taxation operating costs. Ejournal of Tax Research, 1(1) 6492.

Evans, C. (2006). Counting the costs of taxation: An exploration of recent developments. New South Wales: University of New South Wales.

FEB and PWC, (2007): Total tax contribution-studies, URL: ttp://www.feb.be/index.html? page =95 (25/08/2009).

Hanefah, M., Ariff, M., Kasipillai, J. (2002). Compliance costs of small and medium enterprises. Chartered Accountants Journal, 4(1),7394.

Lignier, P. (2006). Are managerial benefits making tax compliance costs more sustainable for small businesses: An investigation of managerial benefit perception by small business taxpayers. Paper presented at the Australasian tax teachers conference (ATTA), University of Canterbury, Christchurch, 19th - 21st January, 2009.

Lignier, P. (2009). The managerial benefits of tax compliance: perception by small business taxpayers. eJournal of Tax Research, 7 , 106-133.

Price Waterhouse Coopers and World Bank, (2009). Paying taxes: The global picture. technical report (Washington: World bank).

Price Water House Coopers, (2008). URL: http://www.pwc.com/be/nl/press/2008-11-11-paying-taxes-2009.jhtm(15/10/2009).

Pillai, K.V. (2000). The compliance costs of vat in the hotel industry in Mauritius, social sciences and humanities and law \& management, 
Research Journal, 3(7), 52-66.

Pope, J. (1993). The compliance costs of taxation in Australia and tax simplification: The issues, Australian. Journal of Management, 18, 69-89.

Pope, J. (1994). Compliance costs of taxation: Policy implications. Australian Tax Forum, 11, 85-121.

Pope, J. (1995). Tax compliance costs of major taxes in Australia in Cedric Sandford, (editor), tax compliance costs: measurement and policy, bath, uk: fiscal publications.

Pope, J. (2005). Tax compliance costs. In taxation: an interdisciplinary approach to research, ed. Margaret lamb, Andy Lymer, Judith freedman and Simon James, 203-16. Oxford, uk: oxford university press.

Salkind, N.J. (1997). Exploring research (3rd Ed), upper saddle river, NJ: Prentice Hall.

Sandford, Cedric. (1995). The rise and rise of tax compliance costs. in cedric sandford, (editor) tax compliance costs measurement and policy. Bath, U.K, fiscal publications in association with the institute for fiscal studies.

Sandford, Cedric, Michael Godwin and Peter Hardwick (1989). Administrative and compliance costs of taxation. Bath, UK: Fiscal publications, 26-121.

Sapiei, N. S., \& Kasipillai, W. (2009). Compliance costs and compliance of corporate taxpayers in Malaysia. Monash University campus doctoral colloquium, http://www.buseco.monash.edu.my/doctoral_colloquium_2009/papers/noor\%20sharoja\%20sapiei.pdf

Sandford, C.T., \& Hasseldine, J. (1992). The compliance costs of business taxes in new Zealand, institute of policy studies, Victoria university of Wellington: Wellington.

Schoonjans, B., Van Cauwenberge, P., Reekmans, C., \& Simoens, G. (2011). A survey on tax compliance costs of Flemish SMEs: Magnitude and determinants. Working Paper, Ghent University, Faculty of Economics and Business.

Tran-Nam, B., Evans, C., Walpole, K. \& Ritchie, K. (2000). Tax Compliance cost: Research methodology and empirical evidence from Australia. National Tax Journal, 53(2), 229-252.

Tran-Nam, B., \& Glover, J. (2005). The GST recurrent compliance costs/benefits of small business in Australia: A case study approach. Journal of Australasian Tax Teachers Association, 237.

Yamane, T. (1967). Elementary sampling theory, prentice-hall, inc, Englewood Cliffs, N.J (1967). 